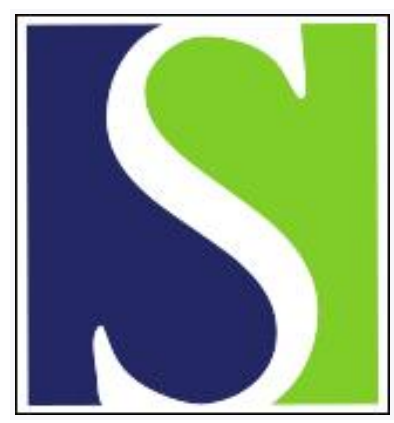

Scand J Work Environ Health 2017;43(5):475-484

https://doi.org/10.5271/sjweh.3647

Published online: 18 May 2017, Issue date: 01 Sep 2017

Autonomic dysregulation in burnout and depression: evidence for the central role of exhaustion

by Kanthak MK, Stalder T, Hill LK, Thayer JF, Penz M, Kirschbaum C

Our study is the first to show burnout associated reductions in vagal-mediated heart rate variability (HRV) in a large population-based sample. These new findings will advance a basic scientific understanding of modulations of autonomic function in burnout disease, research on objective psychometrics of burnout, as well as the ongoing debate on the distinguishability (or lack thereof) of burnout and depression.

Affiliation: Department of Biological Psychology, TU Dresden, Zellescher Weg 19, DE-01069 Dresden, Germany. magdalena.kanthak@tu-dresden.de

Refers to the following texts of the Journal: $2006 ; 32(6): 482-492$ 2015;41(6):565-568

Key terms: affective disorder; autonomic dysregulation; burnout; chronic work stress; depression; dysregulation; exhaustion; heart rate variability; stress; vagal function; work stress

This article in PubMed: www.ncbi.nlm.nih.gov/pubmed/28514792 


\title{
Autonomic dysregulation in burnout and depression: evidence for the central role of exhaustion
}

\author{
by Magdalena K Kanthak, MSc, ${ }^{1}$ Tobias Stalder, PHD, ${ }^{1,2}$ LaBarron K Hill, PhD, ${ }^{3,4}$ Julian F Thayer, PhD, ${ }^{5}$ \\ Marlene Penz, DIPL, ${ }^{1}$ Clemens Kirschbaum, $P h D^{1}$
}

\begin{abstract}
Kanthak MK, Stalder T, Hill LK, Thayer JF, Penz M, Kirschbaum C. Autonomic dysregulation in burnout and depression: evidence for the central role of exhaustion. Scand J Work Environ Health. 2017;43(5);475-484. doi:10.5271/sjweh.3647
\end{abstract}

Objectives Given the important role of the autonomic nervous system (ANS) in stress regulation, astonishingly
little is known about ANS functioning in burnout, a condition arising after prolonged exposure to work-related
stress. The current study sought to investigate ANS modulation, as indexed by vagally-mediated heart rate vari-
ability (HRV), in relation to burnout symptomatology to (i) distinguish associations between the three dimensions
of burnout [emotional exhaustion (EE), cynicism, reduced personal accomplishment] and (ii) investigate overlap
in associations with depressive symptomatology.

Methods Assessments of vagally-mediated HRV (ie, root mean square of successive differences, RMSSD) were conducted in a large population-based sample from the Dresden Burnout Study [ $\mathrm{N}=410$, mean age 42.2, standard deviation (SD) 11.2 years; $33.4 \%$ male]. Vagally-mediated HRV was assessed for 90 seconds during an emotionally-arousing situation (venipuncture, recumbent), a 335 -second recumbent recovery period, and a 335 -second seated resting condition.

Results Results from multiple linear regression analyses revealed that $\mathrm{EE}$ was negatively related to RMSSD during venipuncture ( $(\beta=-0.11, \mathrm{P}=0.03)$ and the seated rest $(\beta=-0.09, \mathrm{P}=0.04)$ even after accounting for established ANS modulators (eg, age, body mass index). This pattern was not observed for the other dimensions of burnout. Exploratory analyses of depressive symptomatology further revealed that RMSSD was significantly and inversely associated with burnout-related symptoms but not with the core criteria of depression (eg, depressed mood).

Conclusions This study presents evidence for a link between exhaustion and reduced vagal function, both in burnout and depression, suggesting that ANS modulations may not be disorder-specific but rather a psychophysiological correlate of an underlying feature shared by both conditions.

Key terms affective disorder; chronic work stress; heart rate variability; stress; vagal function; work stress.

Burnout, a prolonged response to chronic work stress with a growing incidence in industrialized countries, is known to be a risk factor for cardiovascular disease (CVD) even when controlling for classical risk factors $(1,2)$. The exact physiological mechanism(s) underlying this association are, however, still unknown. Given that the autonomic nervous system (ANS) is primarily involved in both the regulation of the cardiovascular system and stress reactivity, this system is a promising starting point for further investigation of this mechanism(s).
The ANS controls numerous visceral functions allowing the body to adequately and flexibly react to environmental challenges. This flexibility is achieved by its two main branches: the sympathetic nervous system (SNS) and the parasympathetic nervous system (PNS), respectively. The two branches act in a complementary manner with SNS activity enabling energy mobilization whereas the PNS rather facilitates energy conservation. Among healthy individuals, the SNS and the PNS are in dynamic balance allowing fast energy mobilization

1 Department of Biological Psychology, TU Dresden, Germany.

2 Clinical Psychology, University of Siegen, Germany.

3 Department of Psychiatry and Behavioral Sciences, Duke University Medical Center, Durham, NC, USA.

4 Center for the Study of Aging and Human Development, Duke University Medical Center, Durham, NC, USA.

5 Department of Psychology, Ohio State University, Columbus, USA.

Correspondence to: Magdalena Kanthak, Department of Biological Psychology, TU Dresden, Zellescher Weg 19, DE-01069 Dresden, Germany. [E-mail: magdalena.kanthak@tu-dresden.de] 
when needed and a rapid decline to energy restoring status after mastering of the internal or external challenge. Chronic stress, however, has been associated with hypoactive parasympathetic modulation via the vagus nerve, resulting in excessive demands on the body and limiting the capacity for energy restoration (3). Given its well-known role as an independent risk factor in CVD $(4,5)$, vagal dysfunction could be the missing link in explaining burnout-associated deterioration of cardiovascular health.

Heart rate variability (HRV) is a well-established marker of vagal function (6). HRV is defined as variations in time between consecutive heart beats (ie, interbeat intervals), caused by the interplay of the two ANS branches at the sinoatrial node (SA) with SNS activity accelerating and PNS activity decelerating heart rate (HR). Due to differences in chemical signaling at the SA node, the vagus nerve is able to modulate $\mathrm{HR}$ on a time scale of milliseconds, whereas SNS responses are much slower $(7,8)$ making high-frequency changes in HRV a relatively pure measure of vagal function (9).

Several studies have revealed associations between reduced vagally-mediated HRV and burnout-related concepts, such as work-stress $(10,11)$, stress-related fatigue $(12,13)$, and exhaustion $(14,15)$. Only five studies, however, have investigated vagally-mediated HRV in conjunction with burnout, conceptualized as work stress-related exhaustion. The results of these studies have been mixed, with one study finding lower basal HRV, but no difference in HRV reactivity to a psychosocial stressor, among individuals with burnout compared to a healthy control group (16). Another study showed increased vagally-mediated HRV after a simulated mentally demanding workday among individuals with burnout compared to controls (17), while three studies failed to find any significant associations between burnout and vagally-mediated HRV (18-20).

There are a number of potential reasons for these inconsistent findings including small and selective samples with respect to sex, age, and professional subgroups. In addition, the lack of a universally-accepted definition of burnout may also contribute to these ambiguous findings. The vast majority of research on burnout relies on the unidimensional conceptualization of the Maslach Burnout Inventory (MBI) total score, which defines burnout as a dichotomous variable comprising the sum score of the sub-dimensions emotional exhaustion (EE), cynicism, and reduced personal accomplishment (21). However, several researchers have questioned the ecological validity of combining the three MBI subscores into a single categorical variable (22-24). Besides a loss of information and reduction in statistical power when converting continuous data into a categorical variable, the lack of reliable and valid cut-off values for the MBI total score suggests the need to separately analyze each of the three MBI sub scores in their continuous form.

The present study aimed to address these limitations by investigating ANS modulations, indexed by vagallymediated HRV, in relation to burnout symptomatology, as well as to examine potential overlap in associations among vagally-mediated HRV, burnout and depressive symptomatology. This was done in a large, heterogeneous sample, using a continuous, multidimensional conceptualization of burnout.

Given the notion that certain dysregulations in biological systems become evident only under stressful conditions (25), we assessed vagally-mediated HRV during different measurement occasions, namely an emotionally-arousing situation, a recumbent recovery period, and a seated resting condition, respectively.

We predicted that greater burnout symptomatology would be associated with reduced vagally-mediated HRV, with possible differences in the magnitude of this relation depending on the respective measurement occasion. Additionally, given the ongoing controversy regarding potential overlap of burnout with depression (review: 26), we also conducted exploratory analyses to examine differences and similarities between depressive and burnout-related symptoms in relation to vagal function.

\section{Methods}

\section{Study population}

Participants were a subsample from the Dresdner Burnout Study (DBS), a large-scale longitudinal study designed to assess psychological, societal and biological risk factors of burnout systematically. Participants of the DBS were recruited in Germany, Austria, and Switzerland via public media with a particular focus on the Dresden area. To accrue a large professionally and socioeconomically diverse sample, age 18-68 years and German language skills were selected as the only inclusion criteria. In addition to an online assessment of a range of psychosocial factors via the official study homepage (www.dresdner-burnout-studie.de), the DBS also includes annual sampling of several biological variables. HRV data used in the current study were obtained during in-person biomarker assessments, conducted from September to October 2015. These biomarker assessments included an emotionally-arousing situation, a recumbent recovery period and a seated resting condition. Based on both, previous evidence showing that venipuncture induced psychological and physiological stress responses (27) as well as significant differences between HR during blood sampling (mean 71.5, SEM 0.54 ) and recovery (mean 70.9, SEM 0.47 ), both recumbently recorded in the current sample $(\mathrm{t}(389)=-2.23$, 
$\mathrm{P}=0.03$ ), venipuncture was used to operationalize this emotionally-arousing situation in the present study. Even though vagally-mediated $\mathrm{HRV}$ was reduced during venipuncture (mean 3.36, SEM 0.03) when compared to the recumbent recovery period (mean 3.38, SEM 0.03), the means did not differ significantly $(\mathrm{t}(389)=0.69, \mathrm{P}=0.49)$.

Altogether, 446 participants accepted our invitation to participate in these biomarker assessments. The sub-sample for the present study was selected based on complete data on all demographical, health-related, and psychological variables resulting in a sample of $\mathrm{N}=416$ participants for the recumbent venipuncture, $\mathrm{N}=402$ for the recumbent recovery condition, and $\mathrm{N}=408$ for the seated resting condition. All participants provided written informed consent to both the online assessment and the biomarker sampling procedure. The ethics committee of TU Dresden approved the study. The authors assert that all procedures contributing to this work comply with the ethical standards of the relevant national and institutional committees on human experimentation and with the Helsinki Declaration of 1975, as revised in 2008. Participants received a monetary compensation of $€ 15$.

\section{Study design and procedure}

The full biomarker sampling procedure lasted approximately 50 minutes and was conducted between 08:0019:00 hours. One week before the biomarker sampling, participants completed an online questionnaire assessing burnout symptomatology, depressive symptomatology, and provided information on demographic and healthrelated factors. After arriving at the laboratory, participants signed the consent forms and were provided with heart rate devices (Polar RS800TM, Polar Electro, Oy, Kempele, Finland). They were then brought to the blood sampling room, where they laid down on a stretcher. HRV was recorded during the blood draw and participants remained in supine position for 6 minutes, during which recordings of recumbent recovery HRV were obtained. Approximately 20 minutes after completion of the recovery, participants were led to a separate room, where 6 minutes of seated resting HRV was assessed.

\section{Self-report measures}

The following demographic and health-related characteristics previously shown to influence cardiac vagal tone (28-33) were assessed: age, sex, alcohol and caffeine consumption (yes/no), smoking (yes/no), and regular physical exercise (yes/no). In addition, body mass index (BMI) was calculated based on participants' self-reported weight and height.

Burnout was assessed with the German version (MBI-GS-D; 34) of the Maslach Burnout Inventory-
General Survey (MBI-GS; 35), which consists of 16 items forming three subscales (EE, cynicism, reduced personal efficacy). The items are rated on a 7-point Likert scale $(0=$ never, $6=$ daily $)$. The weighted MBI total score $(0.4 \times \mathrm{EE}+0.3 \times$ cynicism $+0.3 \times$ reduced personal accomplishment) (36) and the three MBI subscores were considered as continuous variables and analyzed separately.

Depression was measured with the German version (PHQ-9-D; 37) of the Patient Health Questionnaire (PHQ-9; 38). The PHQ-9 consists of nine items, which quantify the frequency, over the last two weeks, of each of the nine diagnostic criteria for a depressive disorder of the Diagnostic and Statistical Manual of Mental Disorders (39). The items are scored on a 4-point ranking scale ( $0=$ not at all, $3=$ nearly every day) and summed up to a continuous variable (PHQ-9 sum score), with higher scores representing higher severity of depression. In order to allow for differentiation between burnoutrelated and not burnout-related depressive symptomatology, separate somatic and cognitive symptom scores were derived within the PHQ-9, accordingly to de Jonge et al (40). More specifically, 4 PHQ-9 items related to burnout symptomatology, namely exhaustion, sleeping problems, changes in appetite and psychomotor agitation/retardation were considered as somatic depressive symptoms, whereas lack of interest, depressed mood, negative feelings about self, concentration problems and suicidal intention were considered burnout atypical cognitive depressive problems.

\section{Heart rate data}

Inter-beat intervals (IBI) were recorded with a Polar RS800 CX system via the corresponding chest belt (Polar Electro OY, Kempele, Finland) during the whole biomarker sampling procedure with a sampling frequency of $1000 \mathrm{hz}$. Of the complete IBI timeline, the following data were used: (i) for the emotionally-arousing situation (venipuncture), the 90-second interval after needle insertion for blood sampling, (ii) a 335-second recumbent recovery interval directly after the 90 -second venipuncture, (iii) a 335-second seated resting condition approximately 20 minutes after completion of the venipuncture. An interval after the venipuncture was chosen to avoid distortion of resting HRV by anticipatory fears. The data were then transferred to the Polar Precision Performance Software (Polar Electro OY, Kempele, Finland) and exported as the raw IBI data for further analysis. The ECG raw data were artefact corrected and the root mean square of successive differences (RMSSD) was calculated by Neurocor Ltd. \& Co. KG (Trier, Germany), according to the guidelines of the Task Force of the European Society of Cardiology and the North American Society of Pacing and Electrophysiology (9) using the NEU- 
ROCOR precision HRV-Algorithm. After detection of R-spikes using a modified Pan-Thompkins-Algorithm, identified artefacts were corrected and HRV measures were calculated.

RMSSD was used to operationalize high frequency variation in heart rate because of its status as an approved short-term measure of HRV reflecting vagal cardiac influence and its robustness against breathing patterns $(9,41)$. Preliminary analyses revealed high positive correlations between RMSSD and frequencybased measures of vagally-mediated HRV, which are also commonly used (correlation coefficients between 0.91 and $0.92, \mathrm{P}<0.001$ ). Despite this, no results of frequency-based HF-HRV measures are presented. The overall pattern of results is identical (data not shown).

\section{Statistical analysis and data exclusion}

RMSSD values at the three measurement occasions were not normally distributed and log transformations were applied to reduce skewness. Furthermore, extreme values (interquartile range of log-transformed RMSSD values $\pm 3 \mathrm{SD}$ ) were excluded resulting in final samples of $\mathrm{N}=410$ at venipuncture, $\mathrm{N}=397$ at recumbent recovery, and $\mathrm{N}=403$ at seated rest, respectively.

Associations between questionnaire scores and RMSSD values during the three measurement occasions were examined by simple linear regression analyses and subsequent hierarchical multiple regression analyses adjusted for potential confounders. Given the high multicollinearity among the MBI total score and its sub-scores [EE: $\mathrm{r}(408)=0.89, \mathrm{P}<0.001$; cynicism: $\mathrm{r}(408)=0.86, \mathrm{P}<0.001$; reduced personal accomplishment: $\mathrm{r}(408)=0.65, \mathrm{P}<0.001$ ], as well as among the sub-scores [EE and cynicism: $\mathrm{r}(408)=0.65, \mathrm{P}<0.001$; EE and reduced personal accomplishment: $\mathrm{r}(408)=0.36$, $\mathrm{P}<0.001$; cynicism and reduced personal accomplishment: $\mathrm{r}(408)=0.43, \mathrm{P}<0.001]$ separate hierarchical regression analyses were conducted for these measures. In a first step, age, sex, BMI, alcohol consumption, smoking, caffeine consumption, and regular physical exercise were entered. Next, the respective MBI score was added to this baseline model to examine the additional predictive value beyond well-known HRV determinants. The significance level was set to 0.05 . All analyses were performed using SPSS Statistics 22 (IBM, Armonk, NY, USA).

\section{Results}

Table 1 provides demographic and health-related characteristics for the sample at venipuncture. These descriptive characteristics were virtually identical for the samples of the recumbent recovery and the seated rest conditions and are, therefore, not depicted here.

Results of the simple linear regression analyses predicting RMSSD at the three measurement occasions based on the MBI total score and its subscales are presented in table 2. EE significantly predicted RMSSD during all three measurement occasions, whereas the MBI total score predicted RMSSD only during veni-

Table 1. Demographic and clinical characteristics for the sample at venipuncture $(\mathrm{N}=410)$. [BMI=body mass index; $\mathrm{MBI}$ total score=Maslach Burnout Inventory general survey total score; $P H Q-9=P a t i e n t$ Health Questionnaire sum score; $\mathrm{PHQ}-9$ somatic=somatic symptom score of the PHQ-9; $\mathrm{PHQ}-9$ cognitive=cognitive symptom score of the $P H Q-9$; RMSSD=root mean of successive differences; $\mathrm{SD}=$ standard deviation].

\begin{tabular}{|c|c|c|c|c|c|}
\hline & Mean & $\mathrm{SD}$ & $\%$ & Range & Scale range \\
\hline Age (years) & 42.17 & 11.18 & & $19-67$ & \\
\hline Sex (male) & & & 33.4 & & \\
\hline BMI $\left(\mathrm{kg} / \mathrm{m}^{2}\right)$ & 25.18 & 4.53 & & $17.30-42.52$ & \\
\hline $\begin{array}{l}\text { Alcohol consumption } \\
\text { (yes) }\end{array}$ & & & 86.1 & .. & \\
\hline Smoking (yes) & . & & 13.9 & .. & \\
\hline $\begin{array}{l}\text { Caffeine consumption } \\
\text { (yes) }\end{array}$ & & & 93.2 & .. & \\
\hline Regular exercise (yes) & & & 67.8 & & \\
\hline $\mathrm{MBI}$ to & 2.25 & 1.17 & $17.3^{\mathrm{a}}$ & $0.00-5.38$ & $0.00-6.00$ \\
\hline Emotional exhaustion & 2.86 & 1.16 & $37.6^{\mathrm{a}}$ & $0.00-6.00$ & -6.00 \\
\hline Cynici & 2.05 & 1.51 & $19.3^{\mathrm{a}}$ & $0.00-6.00$ & -6.00 \\
\hline $\begin{array}{l}\text { Reduced personal } \\
\text { accomplishment }\end{array}$ & 1.64 & 1.13 & $7.6^{\mathrm{a}}$ & $0.00-6.00$ & -6.00 \\
\hline PHQ-9 & 8.39 & 5.32 & & $0.00-27.00$ & 0.0 \\
\hline PHQ-9 som & 4.30 & 2.64 & & $0.00-12.00$ & $0.00-12.00$ \\
\hline $\begin{array}{l}\text { PHQ-9 cognitive } \\
\text { RMSSD }\end{array}$ & 4.10 & 3.04 & & $0.00-14.00$ & $0.00-15.00$ \\
\hline At blood draw & 35.03 & 22.72 & & & 33.80 \\
\hline At recovery & 33.82 & 18.80 & & & $4.41-108.71$ \\
\hline At rest & 35.78 & 22.12 & & & $.6 .16-147.64$ \\
\hline
\end{tabular}

a $\%$ of individuals with serious burnout symptomatic accordingly to cutoff value introduced by Kalimo et al (36).

Table 2. Summary of simple and fully adjusted multiple regression analyses for the prediction of RMSSD (logarithmized) at all three measurement occasions. $[\mathrm{CY}=\mathrm{cynicism}$ (Maslach Burnout Inventory, $\mathrm{MBI}$ ); $\mathrm{EE}=$ =emotional exhaustion (MBI), In_RMSSD=root mean square of successive differences between heart beats, logarithmized; PER=reduced personal accomplishment (MBI)].

\begin{tabular}{|c|c|c|c|c|c|c|}
\hline & \multicolumn{6}{|c|}{ In_RMSSD } \\
\hline & \multicolumn{2}{|c|}{$\begin{array}{c}\text { Venipuncture } \\
(\mathrm{N}=410)\end{array}$} & \multicolumn{2}{|c|}{$\begin{array}{c}\text { Recovery } \\
(\mathrm{N}=397)\end{array}$} & \multicolumn{2}{|c|}{$\begin{array}{c}\text { Rest } \\
(\mathrm{N}=403)\end{array}$} \\
\hline & Simple & Multiple a & Simple & Multiple a & Simple & Multiple $^{\mathrm{a}}$ \\
\hline & $\beta$ & $\beta$ & $\beta$ & $\beta$ & $\beta$ & $\beta$ \\
\hline Model 1: MBI & $-0.10^{b}$ & -0.08 & -0.08 & -0.05 & $-0.10^{b}$ & -0.06 \\
\hline Model 2: EE & $-0.15^{c}$ & $-0.11^{b}$ & $-0.12^{b}$ & -0.06 & $-0.15^{c}$ & $-0.09 b$ \\
\hline Model 3: CY & -0.06 & -0.05 & -0.05 & -0.04 & -0.03 & -0.01 \\
\hline Model 4: PER & -0.00 & -0.00 & -0.00 & -0.01 & -0.03 & -0.03 \\
\hline
\end{tabular}

a Model adjusted for age, sex, body mass index, smoking, caffeine consumption, regular exercise.

b $\mathrm{P}<0.05$.

c $\mathrm{P}<0.01$. 
puncture and seated rest. None of the other two MBI sub-scores explained a significant amount of RMSSD variance in any measurement occasion.

Next, two-step hierarchical regression analyses were performed to test for independent effects of the MBI total score and its sub-scores on RMSSD (table 2). During all three measurement occasions, the baseline model predicted the largest amount of total explained variance in RMSSD (venipuncture: $\mathrm{R}^{2}$ adjusted $=0.06$, $\mathrm{F}(7,402)=4.87, \mathrm{P}<0.001$; recumbent recovery: $\mathrm{R}^{2}$ adjusted $=0.16, \mathrm{~F}(7,389)=11.39, \mathrm{P}<0.001$; seated rest: $\mathrm{R}^{2}$ adjusted $\left.=0.19, \mathrm{~F}(7,395)=14.37, \mathrm{P}<0.001\right)$. Thereby, age was the only baseline model variable, which significantly predicted RMSSD during all measurement occasions (venipuncture: $\beta=-0.25, \mathrm{t}(402)=-4.89, \mathrm{P}<0.001$; recumbent recovery: $\beta=-0.35, \mathrm{t}(389)=-7.18, \mathrm{P}<0.001$; seated rest: $\beta=-0.39, \mathrm{t}(395)=-8.20, \mathrm{P}<0.001)$. Beyond age, BMI at recumbent recovery $(\beta=-0.11, t(389)=-2.28$, $\mathrm{P}=0.02)$ and physical exercise at seated rest $(\beta=-0.17$, $\mathrm{t}(402)=3.65, P<0.001)$ were the only additional significant baseline-model predictors. This pattern did not change with adding the MBI total score or any of its subscale scores to the regression analyses.

The second step of regression analyses (table 1, model 2) provided partial confirmation of the research hypothesis by revealing a significant additional effect of EE on RMSSD at venipuncture $\left(\Delta \mathrm{R}^{2}\right.$ adjusted $=0.01$, $\mathrm{F}(8,401)=4.92, \mathrm{P}<0.001)$ and seated rest $\left(\Delta \mathrm{R}^{2}\right.$ adjusted $=0.01, \mathrm{~F}(8,388)=13.20, \mathrm{P}<0.001)$ when entered after the baseline model. However, neither the MBI total score nor the other MBI sub-scores significantly contributed to RMSSD prediction beyond the baseline model at any measurement occasion.

\section{Exploratory analyses on depressive symptomatology and HRV}

Based on our results for EE as well as previous contentions that the association between burnout and other psychophysiological markers is primarily driven by comorbid depression (26), exploratory analyses were conducted to further examine the interrelations among EE, depression symptomatology and vagally-mediated HRV. As expected, depression symptoms, operationalized by the PHQ-9 sum score, were negatively associated with RMSSD during seated rest $(\mathrm{r}(401)=-0.15, \mathrm{P}=0.003)$ and recumbent recovery $(\mathrm{r}(395)=-0.10, \mathrm{P}=0.047)$. When decomposing the PHQ-9 sum score into a cognitive-affective and a somatic factor, as suggested by de Jonge et al (40), findings revealed that the PHQ-9 somatic symptoms were primarily responsible for this association. In particular, the somatic subscale was significantly inversely associated with RMSSD during all three measurement occasions (venipuncture: $\mathrm{r}(408)=-0.10, \mathrm{P}=0.047$; recumbent recovery: $r(395)=-0.12, \mathrm{P}=0.02$; seated rest: $\mathrm{r}(401)=$ $0.17, \mathrm{P}=0.001$ ), whereas the cognitive symptom score showed associations only during seated rest $(\mathrm{r}(401)=$ $0.11, \mathrm{P}=0.02$ ). Consistent with this pattern, during all three measurement occasions reductions in associations between EE and RMSSD when controlling for depressive symptoms were strongest for the somatic factor and lowest for the cognitive-affective factor (figure 1).

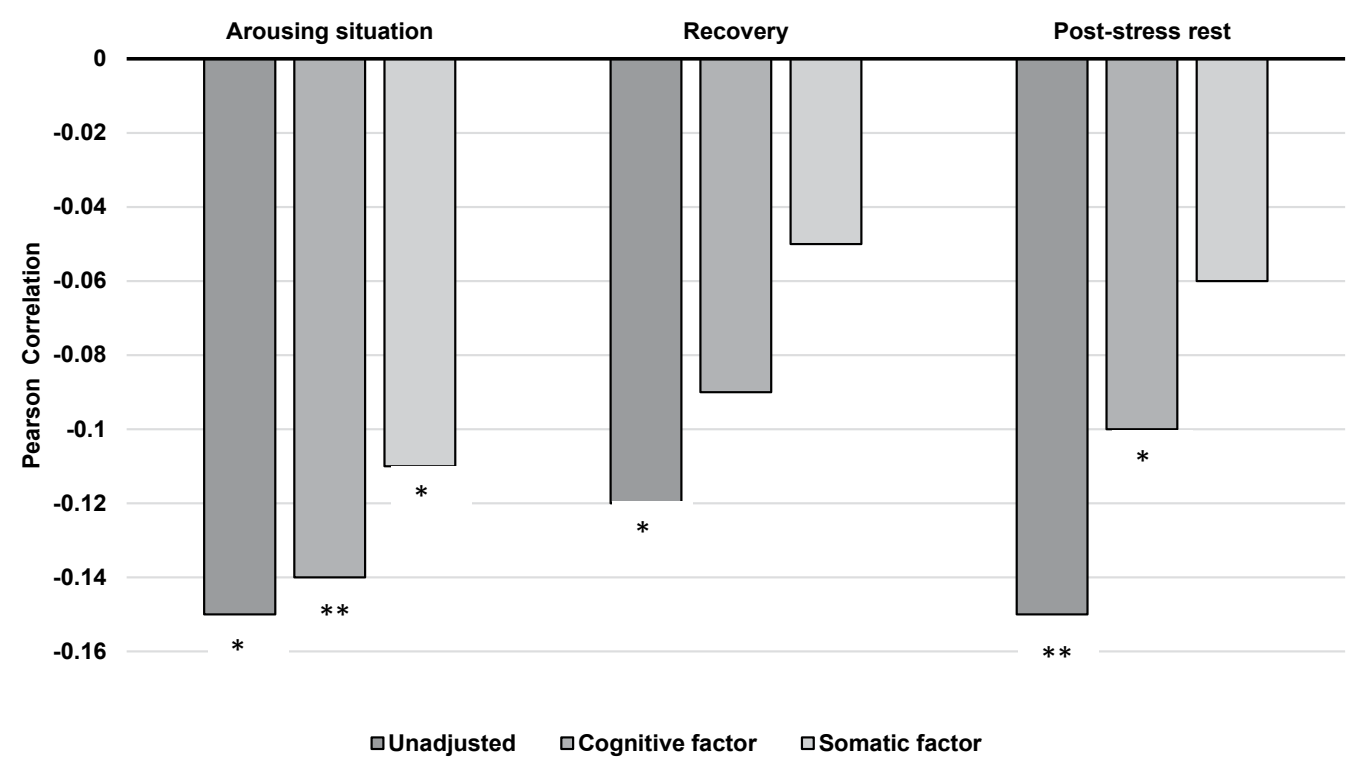

Figure 1. Bivariate and partial correlation coefficients of the association between emotional exhaustion and RMSSD (logarithmized) at the three measurement occasions, unadjusted or adjusted for the PHQ-9 cognitive or somatic factors. ${ }^{*} P<0.05 ;{ }^{* *} P<0.01$. 


\section{Discussion}

The goal of the present study was to examine the association between burnout and vagally-mediated HRV in a large, heterogeneous population-based sample. In partial support of our primary hypothesis, we found that the EE component of burnout was significantly and inversely associated with RMSSD during an emotionally-arousing situation (venipuncture) and a seated resting period, even after accounting for the effects of age, sex, BMI, alcohol and caffeine consumption, smoking, and regular physical exercise. However, neither the MBI total score nor the cynicism or reduced personal accomplishment subscales were associated with vagally-mediated HRV at any measurement occasion when controlling for the influence of covariates.

The current notion that exhaustion yields specific findings when examining associations with measures of parasympathetic function has also emerged from previous research not necessarily focusing on burnout $(14,15,42)$. Previous studies have also reported EE as the primary burnout subscale showing associations with physiological stress markers such as allostatic load (43, 44), and HPA axis function (review: 45, 46). However, to our knowledge, our study is the first to demonstrate the effects of burnout-associated exhaustion with vagal function. Taken together with the well-established link between reduced vagally-mediated HRV and CVD (review: 5), as well as longitudinal evidence showing vital exhaustion to be predictive of CVD (47-50), our results indicate that EE may also be a psychological factor contributing to risk for CVD.

Contrary to our expectations, we did not find the MBI total score to be significantly associated with vagal activity at any measurement period. This is surprising, given that chronic work stress, the causal prerequisite of burnout, has been repeatedly associated with lower vagally-mediated HRV $(10,11)$. Nonetheless, this finding is in line with some previous investigations of burnout (18-20). Indeed, two other studies reported significant effects of burnout on vagally-mediated HRV, albeit in opposite directions, using unidimensional burnout scores. In particular, de Vente et al (16) found reduced baseline HF-HRV amongst individuals endorsing burnout symptoms when compared to a healthy control group. In contrast, Zanstra and colleagues (17) observed a significant increase in HF-HRV in a sample of individuals with burnout, after a simulated mentallydemanding workday. Interestingly, no such pattern was seen in a no-burnout control group. One explanation for these divergent findings are differences in the operationalization of burnout, whereby studies either used different burnout questionnaires with varying cut-off values (17-20) or determined burnout status using a clinical screening procedure (16). Additional methodological variance might be due to the use of categorical (16-18, 20) versus continuous (19) conceptualizations of burnout. Given these methodological differences, it may be premature to draw firm empirically validated conclusions regarding the association between burnout and vagal function. Nonetheless, our finding concerning the outstanding role of EE supports previous indications of considering the relationship between burnout and psychophysiological variables on a symptom level (51).

As a secondary, more exploratory question, we also investigated the overlap of associations between burnout and depression. In line with previous studies showing diminished effects of burnout on health outcomes when controlling for depressive symptomatology $(43,52)$, we found that the introduction of depression attenuated the association between EE and RMSSD. This is not surprising, given the large symptom overlap between burnout, and particularly the EE dimension, with depression, both cross-sectionally $(26,53)$ and longitudinally (54). However, employing the approach described by de Jonge et al (40), our results suggest that the depressive somatic factor, and not the core criteria of depression (namely depressive mood and lack of interest), was primarily responsible for reducing the associations between EE and RMSSD. This is in line with previous research showing that somatic, but not cognitive-affective symptoms mainly accounted for the association between depression and both vagally-mediated HRV (for review see 55, 56) as well as CVD (57-59). Thus, in contrast to previous claims that global depressive symptomatology accounts for the association between burnout and physiological processes, our results indicate that it is the exhaustion-related symptomatology, common to both burnout and depression, which appears to be driving the association with PNS dysregulation.

An advantage of the present study design was that associations between burnout and vagally-mediated HRV were examined at different measurement occasions, allowing for the possibility to observe how/whether the relationship between EE and HRV differs under differing modes of physiological regulation. In line with previous notions of differences between patients and controls being more accented during stressful conditions (25), we observed association between $\mathrm{EE}$ and vagal withdrawal being most pronounced during an emotionally-arousing situation (venipuncture). Keeping in mind the relatively small yet significant effect of venipuncture on HR (physiological index for arousal) in the present study, future research applying more stressful conditions are necessary to extend the knowledge about the contextual requirements for the observability of associations between burnout and vagally-mediated HRV.

In addition, albeit to a lesser extent, we observed associations between $\mathrm{EE}$ and reductions in vagal cardiac 
control during a seated rest condition (ie, 20 minutes after the blood draw). Given the well-validated role of vagally-mediated resting HRV as a trait-like marker of self-regulation, reductions in resting vagally-mediated HRV are of special relevance reflecting an individual's capacity to flexibly and appropriately respond and adapt, both physiologically and behaviorally, to changing environmental demands (60-64). The finding of reduced resting vagally-mediated $\mathrm{HRV}$ indicates that an increase in exhaustion symptoms may be accompanied by impairment in this dynamic regulatory ability, a condition which has previously been associated with increased risk for all-cause morbidity and mortality (5).

No EE-related decrease in RMSSD was found during a recumbent recovery period. Given that impaired recovery processes after acute stress have been suggested as an explanatory mechanism of burnout $(65,66)$, as well as the rather limited extent of emotional arousal induced in the present study, longitudinal studies with a specific focus on recovery processes may nevertheless be promising starting points for research on burnout etiology.

There are also some limitations to be considered. First, our assessment was cross-sectional in nature and does not allow any assertions about causality or directionality of the negative association between vagal function and burnout symptomatology. Furthermore, although we considered several confounding variables, we were unable to account for other factors (ie, previous history of psychiatric disorders, chronic disease and medication intake) that might potentially influence ANS function. Thus, longitudinal investigations incorporating valid and comprehensive medical and psychosocial examinations are necessary in order to illuminate the cause-effect relationship between burnout and autonomic functioning. Second, using blood sampling to induce emotional arousal is not without controversy (27). Even though blood sampling as a naturally occurring stressor has a high ecological validity and our manipulation check using HR indicated that blood sampling induced arousal, future studies should use stronger and longer lasting stressors. Third, because we were unable to obtain resting HF-HRV temporally independently of the emotionally-arousing situation, it remains unclear what role individual differences in baseline vagally-mediated HRV may have played in our findings. Fourth, given the lack of universally accepted diagnostic criteria, we operationalized burnout using the MBI-GS, although we are aware that the MBI-GS has been criticized with regard to several methodological shortcomings (67-69). Nonetheless, taken together that the factorial validity of the MBI has been found to have a superior model fit than 1- or 2-factor burnout models (70-72), as well as the generally good internal consistencies for its subscales, the MBI-GS appears to be the most valid and reliable measure of burnout at the moment. Finally, due to limited data regarding the association of burnout with changes in autonomic function, we acknowledge the relatively high number of statistical tests in the present study to examine this relationship. Thus, our findings should be interpreted with caution, as additional research, including prospective studies, are needed to further validate the present results.

In conclusion, we found $\mathrm{EE}$ to be associated with reduced vagal function during an emotionally-arousing venipuncture and a seated resting condition even when controlling for well-known confounders, in a large population-based sample. The EE component of burnout appears to be a promising starting point for future research attempts exploring the repeatedly documented association between burnout and CVD $(1,2)$. In view of the overlap between burnout and depression, our results suggest that a focus on symptom-based approaches rather than classic diagnostic categories might be particularly fruitful.

\section{Acknowledgments}

The TU Dresden's Institutional Strategy ("The Synergetic University"), which is funded by the Excellence Initiative of the German Federal and State Governments, supported this study. The German Academic Scholarship Foundation supported MKK, and LKH was supported by funding from the National Heart, Lung and Blood Institute [NHLBI] \#HL1217008). The funders were not involved in the design, collection, analysis, interpretation and publication decisions of the data. We acknowledge the essential contributions of Professor Drs Nina Alexander, Angelika Buske-Kirschbaum, Jürgen Hoyer, and Katja Beesdo-Baum and Drs Robert Miller and Lars Pieper for their valuable help regarding the design and the conduction of the Dresdner Burnout Study. Furthermore, the authors express thanks to Elisabeth Altstadt, Marion Augustin, Lysann Kaden, Vera M. Ludwig, Rutger Nagel, Alexander Pauls, Rebekka Röndigs, Kelly Schaunsland, Carolin Scholl, and Sabrina Wallrabenstein for assistance during data collection.

The authors declare no conflicts of interest.

\section{References}

1. Melamed S, Shirom A, Toker S, Berliner S, Shapira I. Burnout and risk of cardiovascular disease: evidence, possible causal paths, and promising research directions. Psych Bull. 2006;132:327-53. https://doi.org/10.1037/00332909.132.3.327.

2. Toker S, Melamed S, Berliner S, Zeltser D, Shapira I. Burnout 
and risk of coronary heart disease: a prospective study of 8838 employees. Psychosom Med. 2012;74:840-7. https://doi. org/10.1097/PSY.0b013e31826c3174.

3. Thayer JF, Lane RD. Claude Bernard and the heart-brain connection: further elaboration of a model of neurovisceral integration. Neurosci Biobehav Reviews. 2009;33:81-8. https://doi.org/10.1016/j.neubiorev.2008.08.004.

4. Thayer JF, Lane RD. The role of vagal function in the risk for cardiovascular disease and mortality. Biol Psych. 2007;74:224 42. https://doi.org/10.1016/j.biopsycho.2005.11.013.

5. Thayer JF, Yamamoto SS, Brosschot JF. The relationship of autonomic imbalance, heart rate variability and cardiovascular disease risk factors. Int J Cardiol. 2009;141:122-31. https:// doi.org/10.1016/j.ijcard.2009.09.543.

6. Kuo TB, Lai CJ, Huang YT, Yang CC. Regression analysis between heart rate variability and Baroreflex-related vagus nerve activity in rats. J Cardiovasc Electrophysiol. 2005;16:864-69. https://doi.org/10.1111/j.15408167.2005.40656.x

7. Saul JP. Beat-to-beat variations of heart rate reflect modulation of cardiac autonomic outflow. Physiology. 1990;5:32-7.

8. Berntson GG, Bigger JT, Eckberg DL, Grossman P, Kaufmann PG, Malik M, et al. Heart rate variability: origins, methods, and interpretive caveats. Psychophysiology. 1997;34:623-48. https://doi.org/10.1111/j.1469-8986.1997.tb02140.x.

9. Task Force of the European Society of Cardiology and the North American Society of Pacing and Electrophysiology. Heart rate variability: standards of measurement, physiological interpretation and clinical use. Circulation. 1996;93:1043-65. https://doi.org/10.1161/01.CIR.93.5.1043.

10. Chandola T, Heraclides A, Kumari M. Psychophysiological biomarkers of workplace stressors. Neurosci Biobehav Reviews. 2010;35:51-7. https://doi.org/10.1016/j. neubiorev.2009.11.005.

11. Jarczok MN, Jarczok M, Mauss D, Koenig J, Li J, Herr $\mathrm{RM}$, et al. Autonomic nervous system activity and workplace stressors - a systematic review. Neurosci Biobehav Reviews. 2013;37:1810-23. https://doi.org/10.1016/j. neubiorev.2013.07.004.

12. Olsson EM, Roth WT, Melin L. Psychophysiological characteristics of women suffering from stress-related fatigue. Stress Health. 2010;26:113-26. https://doi.org/10.1002/ smi.1271.

13. Beaumont A, Burton AR, Lemon J, Bennett BK, Lloyd A, Vollmer-Conna U. Reduced cardiac vagal modulation impacts on cognitive performance in chronic fatigue syndrome. PLoS One. 2012;7:e49518. https://doi.org/10.1371/journal. pone. 0049518 .

14. Watanabe T, Sugiyama Y, Sumi Y, Watanabe M, Takeuchi $\mathrm{K}$, Kobayashi F, et al. Effects of vital exhaustion on cardiac autonomic nervous functions assessed by heart rate variability at rest in middle-aged male workers. Int J Behav Med. 2002;9:68-75. https://doi.org/10.1207/ S15327558IJBM0901_05.

15. Collins S, Karasek R. Reduced vagal cardiac control variance in exhausted and high strain job subjects. Int J Occup Med Environ Health. 2010;23:267-78. https://doi.org/10.2478/ v10001-010-0023-6.

16. de Vente W, van Amsterdam JG, Olff M, Kamphuis JH, Emmelkamp PM. Burnout is associated with reduced parasympathetic activity and reduced HPA axis responsiveness, predominantly in males. Biomed Res Int. 2015; 431725. https://doi.org/10.1155/2015/431725.

17. Zanstra YJ, Schellekens, JM, Schaap C, Kooistra L. Vagal and sympathetic activity in burnouts during a mentally demanding workday. Psychosom Med. 2006;68:583-90. https://doi. org/10.1097/01.psy.0000228012.38884.49.

18. Van Doornen LJ, Houtveen JH, Langelaan S, Bakker AB, van Rhenen W, Schaufeli WB. Burnout versus work engagement in their effects on 24-hour ambulatory monitored cardiac autonomic function. Stress Health. 2009;25:323-31. https:// doi.org/10.1002/smi.1279.

19. Henning MA, Sollers J, Strom JM, Hill AG, Lyndon MP, Cumin D, et al. Junior doctors in their first year: mental health, quality of life, burnout and heart rate variability. Perspect Med Educ. 2014;3:136-43. https://doi.org/10.1007/s40037-0130075-y.

20. Jönsson P, Österberg K, Wallergård M, Hansen ÅM, Garde $\mathrm{AH}$, Johansson $\mathrm{G}$, et al. Exhaustion-related changes in cardiovascular and cortisol reactivity to acute psychosocial stress. Physiol Behav. 2015;151:327-37. https://doi. org/10.1016/j.physbeh.2015.07.020.

21. Maslach C, Jackson SE. The measurement of experienced burnout. J Organ Behav. 1981;2:99-113. https://doi. org/10.1002/job.4030020205.

22. Koeske GF, Koeske RD. Construct validity of the Maslach Burnout Inventory: a critical review and reconceptualization. J Appl Behav Sci. 1981;25:131-44. https://doi. org/10.1177/0021886389252004.

23. Maslach C, Jackson SE, Leiter MP. Maslach Burnout Inventory manual. Mountain View (CA): CPP. Inc., and Davies-Black; 1996.

24. Brenninkmeijer $\mathrm{V}$, vanYperen N. How to conduct research on burnout: advantages and disadvantages of a unidimensional approach in burnout research. J Occup Env Med. 2003;60:116i20. https://doi.org/10.1136/oem.60.suppl_1.i16.

25. Kudielka BM, Wüst S. Human models in acute and chronic stress: assessing determinants of individual hypothalamuspituitary-adrenal axis activity and reactivity. Stress. 2010;13:1-14. https://doi.org/10.3109/10253890902874913.

26. Bianchi R, Schonfeld IS, Laurent E. Burnout-depression overlap: a review. Clin Psychol Rev. 2015;3628-41. https:// doi.org/10.1016/j.cpr.2015.01.004.

27. Weckesser LJ, Plessow F, Pilhatsch M, Muehlhan M, Kirschbaum C, Miller R. Do venepuncture procedures induce cortisol responses? A review, study, and synthesis for stress research. Psychoneuroendocrinology. 2014;46:88-99. https:// doi.org/10.1016/j.psyneuen.2014.04.012.

28. Hayano J, Yamada M, Sakakibara Y, Fujinami T, Yokoyama $\mathrm{K}$, Watanabe Y, et al. Short-and long-term effects of cigarette 
smoking on heart rate variability. Am J Cardiol. 1990;65:84-8. https://doi.org/10.1016/0002-9149(90)90030-5.

29. Rossy LA, Thayer JF. Fitness and gender-related differences in heart period variability. Psychosom Med. 1998;60:773-81. https://doi.org/10.1097/00006842-199811000-00022.

30. Karason K, Mølgaard H, Wikstrand J, Sjöström L. Heart rate variability in obesity and the effect of weight loss. Am J Cardiol. 1999;83:1242-47. https://doi.org/10.1016/S00029149(99)00066-1.

31. Bonnemeier H, Wiegand UK, Brandes A, Kluge N, Katus HA, Richardt G, et al. Circadian profile of cardiac autonomic nervous modulation in healthy subjects. J Cardiovasc Electrophysiol. 2003;14:791-99. https://doi.org/10.1046/ j.1540-8167.2003.03078.x.

32. Thayer JF, Hall M, Sollers JJ, Fischer JE. Alcohol use, urinary cortisol, and heart rate variability in apparently healthy men: Evidence for impaired inhibitory control of the HPA axis in heavy drinkers. Int J Psychophysiol. 2006;59:244-50. https:// doi.org/10.1016/j.ijpsycho.2005.10.013.

33. Koenig J, Jarczok MN, Kuhn W, Morsch K, Schäfer A, Hillecke TK, et al. Impact of caffeine on heart rate variability: a systematic review. J Caffeine Res. 2013;3:22-37. https://doi. org/10.1089/jer.2013.0009.

34. Büssing A, Glaser J. Deutsche Fassung des Maslach Burnout Inventory-General Survey (MBI-GS-D). München: Technische Universität, Lehrstuhl für Psychologie; 1999.

35. Schaufeli WB, Leiter MP, Maslach C, Jackson SE. Maslach Burnout Inventory-General Survey. Maslach C, Jackson SE, Leiter MP, editors. The Maslach Burnout Inventory-Test Manual. 3rd ed. Palo Alto (CA): Consulting Psychologists Press; 1996.

36. Kalimo R, Pahkin K, Mutanen P, Topipinen-Tanner S. Staying well or burning out at work: work characteristics and personal resources as long-term predictors. Work Stress. 2003;17:10922. https://doi.org/10.1080/0267837031000149919.

37. Löwe BLSR, Spitzer RL, Zipfel S, Herzog W. Gesundheitsfragebogen für Patienten (PHQ-9). Manual und Testunterlagen. 2. Auflage [PRIME MD Patient Health Questionnaire (PHQ) - German version. 2nd ed.]. Karlsruhe: Pfitzer; 2002.

38. Kroenke K, Spitzer RL, Williams JBW. The PHQ-9: validity of a brief depression severity measure. J Gen Intern Med. 2001;16:606-13. https://doi.org/10.1046/j.15251497.2001.016009606.x.

39. American Psychiatric Association. Diagnostic and statistical manual of mental disorders. 4th ed. Washington (DC): American Psychiatric Association; 2000.

40. de Jonge P, Mangano D, Whooley MA. Differential association of cognitive and somatic depressive symptoms with heart rate variability in patients with stable coronary heart disease: findings from the Heart and Soul Study. Psychosom Med. 2007;69:735-9. https://doi.org/10.1097/ PSY.0b013e31815743ca.

41. Hill LK, Siebenbrock A., Sollers JJ, Thayer JF. Are all measures created equal? Heart rate variability and respiration.
Biomed Sci Instrum. 2009;45:71-6.

42. Keltikangas-Järvinen L, Heponiemi T. Vital exhaustion, temperament, and cardiac reactivity in task-induced stress. Biol Psych. 2004;65:121-35. https://doi.org/10.1016/S03010511(03)00112-1.

43. Bellingrath S, Weigl T, Kudielka BM. Chronic work stress and exhaustion is associated with higher allostastic load in female school teachers: original Research Report. Stress. 2009;12:3748. https://doi.org/10.1080/10253890802042041.

44. Juster R-P, Sindi S, Marin M-F, Perna A, Hashemi A, Pruessner $\mathrm{JC}$, et al. A clinical allostatic load index is associated with burnout symptoms and hypocortisolemic profiles in healthy workers. Psychoneuroendocrinology. 2011;36:797-805. https://doi.org/10.1016/j.psyneuen.2010.11.001.

45. Kudielka BM, Bellingrath S, Hellhammer DH. Cortisol in burnout and vital exhaustion: an overview. G Ital Med Lav Ergon. 2006;28:34-42.

46. Chida Y, Steptoe A. Cortisol awakening response and psychosocial factors: a systematic review and meta-analysis. Biol Psych. 2009;80:265-78. https://doi.org/10.1016/j. biopsycho.2008.10.004.

47. Cole SR, Kawachi I, Sesso HD, Paffenbarger RS, Lee IM. Sense of exhaustion and coronary heart disease among college alumni. Am J Cardiol. 1999;84:1401-5. https://doi. org/10.1016/S0002-9149(99)00585-8.

48. Prescott E, Holst C, Grønbæk M, Schnohr P, Jensen G, Barefoot J. Vital exhaustion as a risk factor for ischaemic heart disease and all-cause mortality in a community sample. A prospective study of 4084 men and 5479 women in the Copenhagen City Heart Study. Int J Epidemiol. 2003;32:990 7. https://doi.org/10.1093/ije/dyg235.

49. Lindeberg SI, Rosvall M, Östergren PO. Exhaustion predicts coronary heart disease independently of symptoms of depression and anxiety in men but not in women. $\mathrm{J}$ Psychosom Res. 2012;72:17-21. https://doi.org/10.1016/j. jpsychores.2011.09.001.

50. Schnohr P, Marott JL, Kristensen TS, Gyntelberg F, Grønbæk $\mathrm{M}$, Lange $\mathrm{P}$, et al. Ranking of psychosocial and traditional risk factors by importance for coronary heart disease: the Copenhagen City Heart Study. Eur Heart J. 2015;36:1385-93. https://doi.org/10.1093/eurheartj/ehv027.

51. Danhof-Pont MB, van Veen T, Zitman FG. Biomarkers in burnout: a systematic review. J Psychosom Res. 2011;70:50524. https://doi.org/10.1016/j.jpsychores.2010.10.012.

52. Hintsa T, Elovainio M, Jokela M, Ahola K, Virtanen M, Pirkola S. Is there an independent association between burnout and increased allostatic load? Testing the contribution of psychological distress and depression. J Health Psychol. 2014;21:1576-86. https://doi. org/10.1177/1359105314559619.

53. Schaufeli W, Enzmann D. The burnout companion to study and practice: a critical analysis. London: Taylor and Francis; 1998.

54. Bianchi R, Schonfeld IS, Laurent E. Burnout does not help predict depression among French school teachers. Scand J Work Environ Health. 2005;41:565-8. https://doi. org/10.5271/sjweh.3522. 
55. Kemp AH, Quintana DS, Gray MA, Felmingham KL, Brown $\mathrm{K}$, Gatt JM. Impact of depression and antidepressant treatment on heart rate variability: a review and meta-analysis. Biol Psychiatry. 2010;67:1067-74. https://doi.org/10.1016/j. biopsych.2009.12.012.

56. BassettD. A literature review of heart rate variability in depressive and bipolar disorders. Aust N Z J Psychiatry. 2015;50:793804. https://doi.org/10.1177/0004867416652734.

57. Schiffer AA, Pelle AJ, Smith OR, Widdershoven JW, Hendriks EH, Pedersen SS. Somatic versus cognitive symptoms of depression as predictors of all-cause mortality and health status in chronic heart failure. J Clin Psychiatry. 2009;70:1667-73. https://doi.org/10.4088/JCP.08m04609.

58. Smolderen KG, Spertus JA, Reid KJ, Buchanan DM, Krumholz HM, Denollet J, et al. The association of cognitive and somatic depressive symptoms with depression recognition and outcomes after myocardial infarction. Circ Cardiovasc Qual Outcomes. 2009;2:328-37. https://doi.org/10.1161/ CIRCOUTCOMES.109.868588.

59. Roest AM, Thombs BD, Grace SL, Stewart DE, Abbey SE, de Jonge. Somatic/affective symptoms, but not cognitive/ affective symptoms, of depression after acute coronary syndrome are associated with 12-month all-cause mortality. J Affect Disord. 2011;13:158-63. https://doi.org/10.1016/j. jad.2010.11.018.

60. Appelhans BM, Luecken LJ. Heart rate variability as an index of regulated emotional responding. Rev Gen Psychol. 2006;10:229-40. https://doi.org/10.1037/10892680.10.3.229.

61. Segerstrom SC, Nes LS. Heart rate variability reflects self-regulatory strength, effort, and fatigue. Psychol Sci. 2007;18:275-81. https://doi.org/10.1111/j.14679280.2007.01888.x.

62. Thayer JF, Åhs F, Fredrikson M, Sollers JJ, Wager TD. A metaanalysis of heart rate variability and neuroimaging studies: implications for heart rate variability as a marker of stress and health. Neurosci Biobehav Reviews. 2012;36:747-56. https:// doi.org/10.1016/j.neubiorev.2011.11.009.

63. Gillie BL, Vasey MW, Thayer JF. Heart rate variability predicts control over memory retrieval. Psychol Sci. 2014;25:458-65. https://doi.org/10.1177/0956797613508789.
64. Williams DP, Cash C, Rankin C, Bernardi A, Koenig J, Thayer JF. Resting heart rate variability predicts self-reported difficulties in emotion regulation: a focus on different facets of emotion regulation. Front Psychol. 2015;6:261. https://doi. org/10.3389/fpsyg.2015.00261.

65. Geurts SA, Sonnentag S. Recovery as an explanatory mechanism in the relation between acute stress reactions and chronic health impairment. Scand J Work Environ Health. 2006;32:482-92. https://doi.org/10.5271/sjweh.1053.

66. Söderström M, Jeding K, Ekstedt M, Perski A, Åkerstedt T. Insufficient sleep predicts clinical burnout. J Occup Health Psychol. 2012;17:175-83. https://doi.org/10.1037/a0027518.

67. Demerouti E, Bakker AB, Nachreiner F, Schaufeli WB. The job demands-resources model of burnout. J Appl Psychol. 2001;86:499-512. https://doi.org/10.1037/00219010.86.3.499.

68. Bouman AM, Te Brake H, Hoogstraten J. Significant effects due to rephrasing the Maslach Burnout Inventory's personal accomplishment items [Electronic Version]. Psychol Rep. 2002;91:825-6. https://doi.org/10.2466/pr0.2002.91.3.825.

69. Shirom A. Job-related burnout: a review. Quick JC, Tetrick LE, editors. Handbook of occupational health psychology. Washington (DC): American Psychological Association; 2003. p. 245-64. https://doi.org/10.1037/10474-012.

70. Schutte N, Toppinen S, Kalimo R, Schaufeli W. The factorial validity of the Maslach Burnout Inventory-General Survey (MBI-GS) across occupational groups and nations. J Occup Organ Psychol. 2000;73:53-66. https://doi. org/10.1348/096317900166877.

71. Schaufeli WB, Bakker AB, Hoogduin K, Schaap C, Kladler A. On the clinical validity of the Maslach Burnout Inventory and the Burnout Measure. Psychol Health. 2001;16:565-82. https://doi.org/10.1080/08870440108405527.

72. Bakker AB, Demerouti E, Schaufeli, WB. Validation of the Maslach burnout inventory-general survey: an internet study. Anxiety Stress Coping. 2002;15:245-60. https://doi.org/10.1 080/1061580021000020716.

Received for publication: 21 November 2016 